\section{HARNESS THE POWER OF LED}

NSK is confident the whole dental team will be impressed by their growing product portfolio, which is about much more than handpieces and turbines.

At BDTA Dental Showcase, on stand D08, NSK will unveil their new full line up of LED options. Practitioners are already experiencing the powerful benefits of LED using NSK LED couplings for NSK, KaVo and Sirona. Now Ti-Max $\mathrm{X}$ Series turbines with integral LED are available from NSK for both Wet and Bien Air.

The premium Ti-Max X Series is made of lightweight, wear resistant titanium. ISB ceramic ball bearings ensure reliability and low noise levels, while the DURACOAT surface treatment optimises durability and is resistant to scratches, shock and repeated autoclaving. The patented Clean Head System reduces the risk of cross contamination and combined with the Quattro Water Spray and solid cellular glass rod optics, creates a powerful turbine that enables you to carry out procedures with confidence and accuracy.

The incorporation of LED across the NSK range gives all practitioners illumination equivalent to daylight, improving visibility and enhancing treatment.

The full product range will be available for demonstration.

Reader response number 70

\section{IN THE SADDLE WITH ABSOLUTE DISINFECTION}

An elective study by fourth year dental students at Glasgow University confirmed Bambach's Saddle Seat as product of choice to combat and prevent lower back pain while at work in the dental surgery. Forty-three percent of respondents to the survey chose the Bambach Saddle Seat as a treatment and preventive measure for back pain (http://hdl.handle.net/1905/499).

The Bambach Saddle Seat is a scientifically designed and proven solution, endorsed by the Australian Physiotherapy Association, as it helps the pelvis attain its preferred neutral position. The spine naturally maintains its stress-free ' $S$ ' shape which negates back, shoulder and neck pain.

Bambach have also attracted considerable interest in their unique Saniswiss biosanitizer wipes and spray. Without resorting to alcohol or aldehydes (proven health hazards) Saniswiss biosanitizer 'digests' viruses, bacteria and fungi. It converts such germs to water using a unique and patented super-oxygenised solution.

Saniswiss biosanitizer is a water based product so it will not evaporate from surfaces in seconds like other brands, meaning it is even more effective at killing germs. It also has a pleasant aroma, does not leave a residue even when used on glass and will not cause damage to leather or vinyl used on chairs and stools.

To find out more and for special offers and details of Bambach's 30-day Saddle Seat trial, head to stand B03 at BDTA Dental Showcase.

Reader response number 71

\section{HIGH PRECISION HANDPIECES}

Bien-Air's brand new high precision Powercare piezon scaler is perfect for all prophylactic supra-gingival and sub-gingival scaling and is extremely effective at removing all deposits. The Powercare unit monitors and automatically adjusts the power needed for each operation, guaranteeing optimal efficiency and increased comfort for your patients.

Bien-Air's range also includes the Bora Blackline and Metaline turbines. Due to the carbon fibre handle these incredibly lightweight handpieces are easy to manoeuvre and offer improved resistance to wear, friction, torsion and impacts. LED lighting is standard with all Blackline tur- bines. The Bora is extra quiet due to the ceramic ball bearings and is built to last.

Fitted with an integral non-return valve to help with infection control and large push buttons for easy bur removal, these turbines incorporate an anti-heat system to avoid heat build-up during treatment. The triple spray diffuser with three separate air and water ports ensures optimum cooling even at high speeds.

Visit stand R10 at Dental Showcase to see these products plus the newly launched MCX Micromotor - shorter and lighter than the MX but with the same power and at a lower cost.

Reader response number 72

\section{COMFORTABLE DIGITAL IMPRESSIONING}

At BDTA Dental Showcase 2010 dentists can experience the difference that the Lava chairside oral scanner (COS) from 3M ESPE could make to the quality of their patient care.

The COS is an electric toothbrushsized digital intra-oral scanner with unique manoeuvrability which delivers 3D in-motion images of patients' teeth. It is a less intrusive, more comfortable solution to impression taking and brings dentists closer to clinical perfection by improving the accuracy of dental restorations and the quality of interaction between dentist and patient.

3M ESPE manufactures more than 2,000 dental products and services including restoratives, crowns and bridges, temporisation, impressioning, cements, preventive and cosmetic dentistry.

To find out more and to see a demonstration of the Lava COS and digital workflow visit stand L02.

Reader response number 73

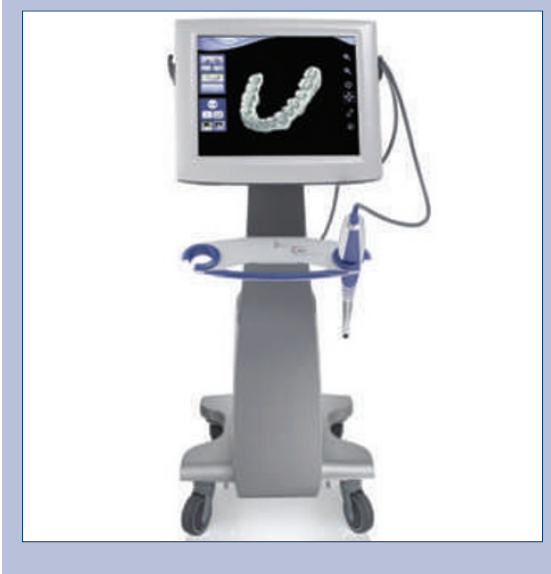

